\title{
Density Profile as a Tool in Assessing Quality of New Composite
}

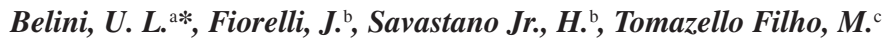 \\ ${ }^{a}$ Department of Biological and Veterinary Science, Federal University of Santa Catarina - UFSC, \\ Rod. Ulysses Gaboardi, Km 3, CEP 89520-000, Curitibanos, SC, Brazil \\ ${ }^{\mathrm{b}}$ Department of Biosystems Engineering, Faculty of Animal Science and Food Engineering - FZEA, \\ University of São Paulo - USP, Av. Duque de Caxias Norte, 225, \\ CEP 13635-900, Pirassununga, SP, Brazil \\ ${ }^{\mathrm{c}}$ Department of Forest Sciences, Luiz de Queiroz College of Agriculture - ESALQ, \\ University of São Paulo - USP, Av. Pádua Dias, 11, CP 9, CEP 13418-900, Piracicaba, SP, Brazil
}

Received: January 30, 2013; Revised: July 19, 2013

\begin{abstract}
This paper present a study to apply the X-ray densitometry technique in obtaining density profiles, along the thickness of new composites made from eucalyptus fibers and sugarcane bagasse particles. Experimental panels were made in treatments with different percentages of both raw materials and bonded with two urea formaldehyde resin percentages, $13 \%$ and $16 \%$, with target density of $750 \mathrm{~kg} \mathrm{~m}^{-3}$, obtaining density profiles and qualitative variables of maximum, medium and minimum densities. The results indicated that the dosage of resin at $16 \%$ promoted greater homogeneity in the profile formats and statistical similarity between the minimum density values in the different treatments, which refers to performance as to the internal bond. The density profiles along the thickness showed variations of the panel frame and provided important quality information, applied to the press cycle setting and indications of its technological performance, expanding the possibilities of raw material parameter diagnosis and the panel manufacturing processes.
\end{abstract}

Keywords: non-destructive testing, waste and subproducts industrials, composites materials, sustainability

\section{Introduction}

Obtaining density profiles in fibreboard and particleboard is essential to control production, becoming an important measure of their quality and application and allowing inferences about the mechanical properties of the panels and press cycle calibrations ${ }^{1-4}$.

In making the panels, the formation of the density profile during the manufacturing process is dependent on the interaction between temperature, humidity and pressure applied to the fibers during pressing ${ }^{5,6}$.

The high, minimum and average apparent density values of panels are indicators of adequate properties of perpendicular tensile strength, with the resistence being able to be increased by changing the density gradient along its thickness 5,7 . Thus it can become a significant tool in the analysis of new technological composites made with alternative raw materials ${ }^{8-12}$.

In Brazil, there is growing demand for use of alternative fibrous resources due to their availability, low cost and the ability to obtain products with higher added value. In this context, emphasis is given to the sugarcane bagasse, with a production of 160 million tons in the 2008/2009 harves and that, along with the high productivity eucalyptus forests that occupy more than 4.5 million hectares, may become compositional elements to obtain panels with new possibilities for multiple applications, which adds to the

*e-mail: ugo.belini@ufsc.br modern technological facilities installed for fibreboard and particleboard manufacture ${ }^{13-15}$.

In the present study, we analyzed density profiles, obtained by X-ray densitometry, of new panels made with different percentages of sugarcane bagasse (Saccharum sp.) and eucalyptus fiber (Eucalyptus grandis) and bound with two levels of urea-formaldehyde resin (13\% and 16\%) and made inferences on the performance of the technological properties and possible applications of the new composites.

\section{Material and Methods}

\subsection{Experimental treatments and test panels}

The research activities were developed in 2 stages:

Step A: 5 Treatments were evaluated (Table 1A) regarding mixture percentages of eucalyptus fibers and bagasse particles, producing two panels per treatment for a total of ten panels.

Step B: 12 treatments were evaluated (Table 1B) regarding mixture percentages of eucalyptus fibers and bagasse particles and two different percentages of ureaformaldehyde resin (UF, 13 and 16\%), with four panels per treatment for a total of forty-eight panels. In making the panels, the percentage of bagasse ranged from 0 to $25 \%$ proportion, considering that the eucalyptus fibers constitute the main raw material and bagasse is a supplement. 
Table 1. Treatments proposed for panel manufacture in steps A and B.

\begin{tabular}{|c|c|c|c|c|c|}
\hline \multirow[t]{2}{*}{ Step } & \multirow[t]{2}{*}{ Treatment } & \multirow[t]{2}{*}{ Resin Content } & \multirow[t]{2}{*}{ Wax } & \multicolumn{2}{|c|}{ Raw Material Content (\%) } \\
\hline & & & & Eucalyptus fibers & Bagasse particles \\
\hline & $\left(\mathbf{N}^{0}\right)$ & (\%/dry fiber) & (\%/dry fiber) & $(\%)$ & $(\%)$ \\
\hline \multirow{5}{*}{$\mathbf{A}$} & 1 & \multirow{5}{*}{14} & \multirow{5}{*}{0.8} & 100 & 0 \\
\hline & 2 & & & 75 & 25 \\
\hline & 3 & & & 50 & 50 \\
\hline & 4 & & & 25 & 75 \\
\hline & 5 & & & 0 & 100 \\
\hline \multirow{12}{*}{$\mathbf{B}$} & 1 & 13 & \multirow{12}{*}{0.8} & 100 & 0 \\
\hline & 2 & 16 & & 100 & 0 \\
\hline & 3 & 13 & & 95 & 5 \\
\hline & 4 & 16 & & 95 & 5 \\
\hline & 5 & 13 & & 90 & 10 \\
\hline & 6 & 16 & & 90 & 10 \\
\hline & 7 & 13 & & 85 & 15 \\
\hline & 8 & 16 & & 85 & 15 \\
\hline & 9 & 13 & & 80 & 20 \\
\hline & 10 & 16 & & 80 & 20 \\
\hline & 11 & 13 & & 75 & 25 \\
\hline & 12 & 16 & & 75 & 25 \\
\hline
\end{tabular}

The studies show that in Step A pressing conditions for panels with more than $25 \%$ bagasse particles obligatorily must be change, with adjustments in the pressing cycle (temperature, pressure and time), and may interfere with the physical-mechanical analyses of panels.

The results of the analysis of panels prepared in this step guided the development of Step B with increasing values of a randomized mixture of 5 to $25 \%$ proportion of bagasse particles in relation to the eucalyptus fibers. A blend of up to $25 \%$ bagasse in the manufacture of panels was defined for a (i) detailed characterization of panels with small additions of raw materials, (ii) appropriate product standards and consumer markets, (iii) greater acceptance of using small percentage of new raw materials, (iv) better adequacy of the raw material supply chain and (v) capability of being used under current manufacturing conditions.

\subsection{Preparation of fibrous samples}

After collect, bagasse and eucalyptus fiber was dry under $60{ }^{\circ} \mathrm{C}$ during $24 \mathrm{~h}$, to reduce the moisture to $7 \pm 3 \%$.

Bagasse samples were classified granulometrically in Produtest (São Paulo, Brazil), model G vibrating equipment, experimentally applying $12.0 \mathrm{~mm}, 6.3 \mathrm{~mm}, 3.15 \mathrm{~mm}$, $2.0 \mathrm{~mm}$ and $<2.0 \mathrm{~mm}$ (collector) mesh. All fibrous material that passed through the $2.0 \mathrm{~mm}$ sieve, and was retained in the collecting vessel was used in the panels manufacture. This same aperture $(2.0 \mathrm{~mm})$ was used for selecting bagasse particles and in classifying particles from Arundo donax L., a Mediterranean tree species, for particleboard manufacture ${ }^{10.16}$.

Samples of fibers and other cellular components from eucalyptus wood were collected after the wood chip refining and prior to the addition of sizing additives. The refining conditions were (i) heating time $=4$ min, (ii) digestion pressure $=8.0 \mathrm{bar}$, (iii) specific refining consumption $(\mathrm{SEC})=100 \mathrm{kWh} / \mathrm{t}$, standard practice in industrial scale for MDF manufacture.

\subsection{Panels manufacture}

The eucalyptus fibers and bagasse particles were arranged inside the blender and mixed while adding urea formaldehyde resin and wax emulsion through nozzles with compressed air for homogenization of the fibrous matrix. Subsequently, the fiber and particle mass was manually laid out in a forming box and transported to a hydraulic press, only needed to decrease mat thickness.

Then, the mat was prepared in a Siempelkamp press (Krefeld, Germany) the press cycle being: $10 \mathrm{~s}$ pressure from 0 to $100 \mathrm{~N} \mathrm{~cm}^{-2}, 5 \mathrm{~s}$ at $100 \mathrm{~N} \mathrm{~cm}^{-2}, 20 \mathrm{~s}$ reduction to $20 \mathrm{~N} \mathrm{~cm}^{-2}, 15 \mathrm{~s}$ to reduce to $10 \mathrm{~N} \mathrm{~cm}^{-2}$, pressure maintained for $50 \mathrm{~s}$, increasing to $30 \mathrm{~N} \mathrm{~cm}^{-2}$ in $10 \mathrm{~s}$, maintained for $40 \mathrm{~s}$, with further reduction to $0 \mathrm{~N} \mathrm{~cm}^{-2}$ for $5 \mathrm{~s}$. After pressing, the samples were conditioned at room temperature and laterally trimmed to the final dimensions of $370 \times 370 \mathrm{~mm}$, nominal thickness of $15.0 \mathrm{~mm}$, target density of $750 \mathrm{~kg} \mathrm{~m}^{-3}$ and moisture content of $8 \pm 2 \%$.

\subsection{Density profiles characterization}

The panels density characterization profiles along the thickness were obtained from a GreCon densitometer (Hannover, Germany) Model DA-X which is used in industry and the laboratory and is standard equipment for obtaining and interpreting the densitometric profile of fibreboard and particleboard.

For each treatment, $50 \times 50 \mathrm{~mm}$ samples were marked, cut and maintained in an acclimatization chamber $\left(\mathrm{T}=20^{\circ} \mathrm{C}\right.$ and $\left.\mathrm{RH}=60 \%\right)$. Figure 1 illustrates the equipment (Figure 1A), sample cutting steps (Figures 1B and 1C), the 
layout in the sample holder and start of the profile reading along the thickness (Figure 1D and 1E) and the illustration of an experimental profile (Figure 1F) on a computer screen.

For step A (panel contents 0-25-50-75-100\% bagasse with $14 \%$ of resin) three density profiles along the thickness were obtained for each treatment, one specimen from a board and another two specimens from another board, totaling 15 profiles. For step B (panels with levels of 0-5-10-15-20-25\% bagasse) 6 apparent density profiles along the thickness were obtained for each treatment, two specimens from three different boards, at the resin dosages of $13 \%$ and $16 \%$, totaling 72 profiles.

Quantitative data profile values obtained were: (i) maximum density (mean between upper and lower faces), (ii) average density and (iii) minimum density as shown in
Figure 2. For obtaining the densitometric profile, the device operated under the following conditions: voltage $33 \mathrm{kV}$, current of $0-1 \mathrm{~mA}$ radiation angle of $11^{\circ}$, initial and final beam collimation of 100 and $50 \mu \mathrm{m}$, respectively.

\section{Results and Discussion}

Step A: apparent density profiles along the thickness of the panels with 0-25-50-75-100\% bagasse, made with $14 \%$ resin (Figure 3 ) are characterized by higher densities $\left(961 \mathrm{~kg} \mathrm{~m}^{-3}\right)$ on their faces, with gradual reduction and lower density $\left(646 \mathrm{~kg} \mathrm{~m}^{-3}\right)$ at their centers, with a tendency to stabilize in the interior of the panel. The density profile of the panel is similar to the letter "M", being reported for MDF panels manufactured with fibrous elements from different

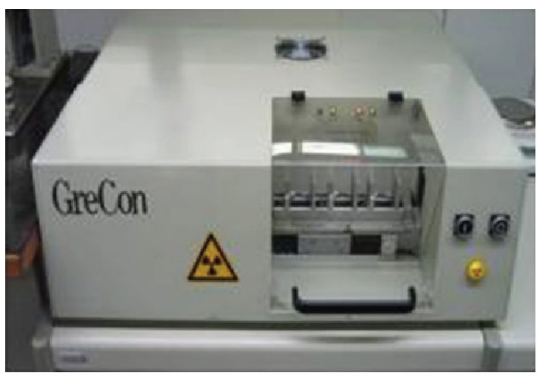

(a)

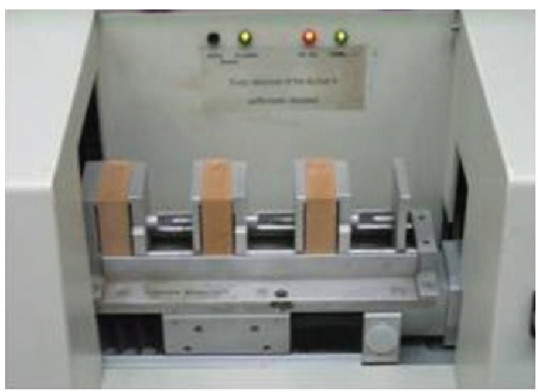

(d)

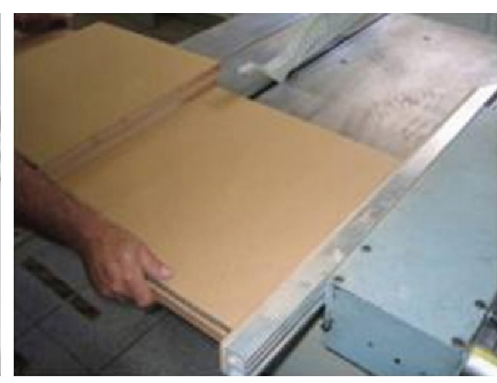

(b)

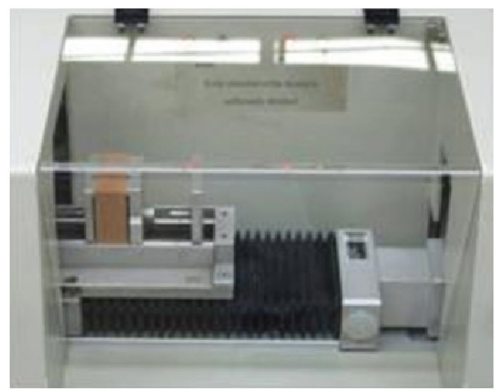

(e)

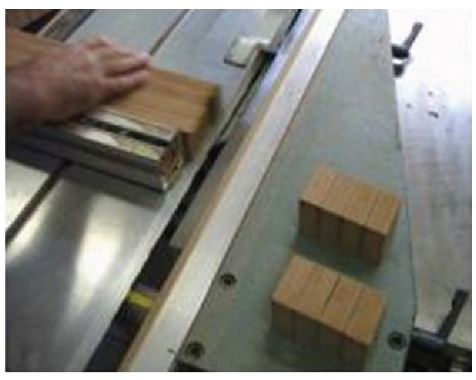

(c)

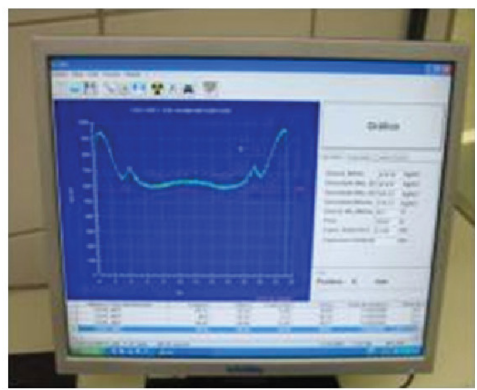

(f)

Figure 1. Density profile of panels by X-ray densitometry (A) X-ray densitometer GreCon DA-X, (B and C) cutting the panel samples; (D) samples arranged in the holder; (E) displacement of the support to the reading chamber; (F) profile and density values of the panel.

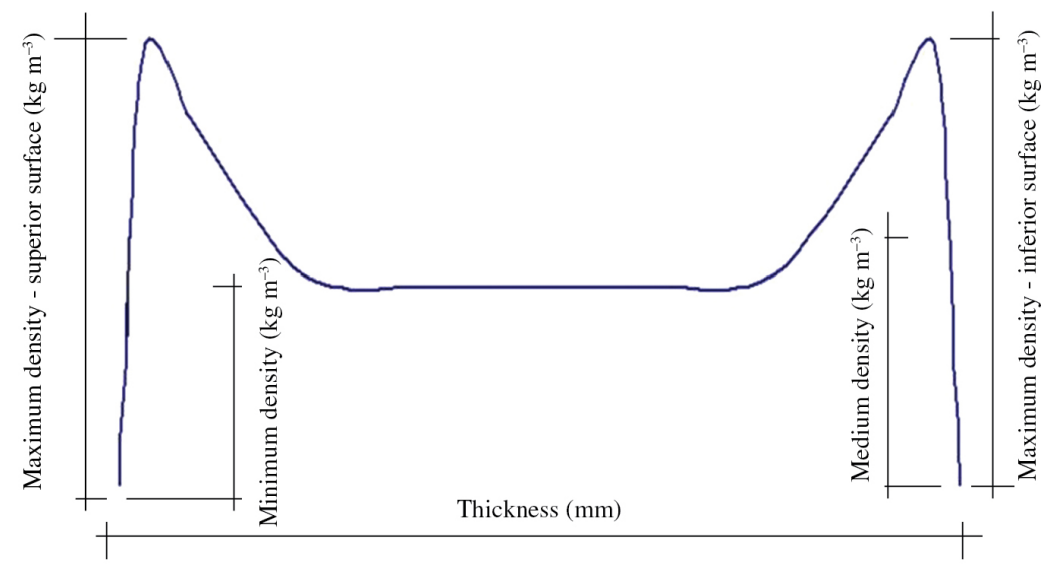

Figure 2. Quantitative parameters evaluated in the density profile. 
species $^{3,6,17}$. On the other hand, the density profiles are applied in the detection of decreased density in the central region related to raw material and panel manufacturing processes such as those found in the panels with $75 \%$ (Figure 3D) and 100\% (Figure 3E) bagasse, indicative of incomplete resin cure, particle size and anatomical structure of the particles in the inner panel.

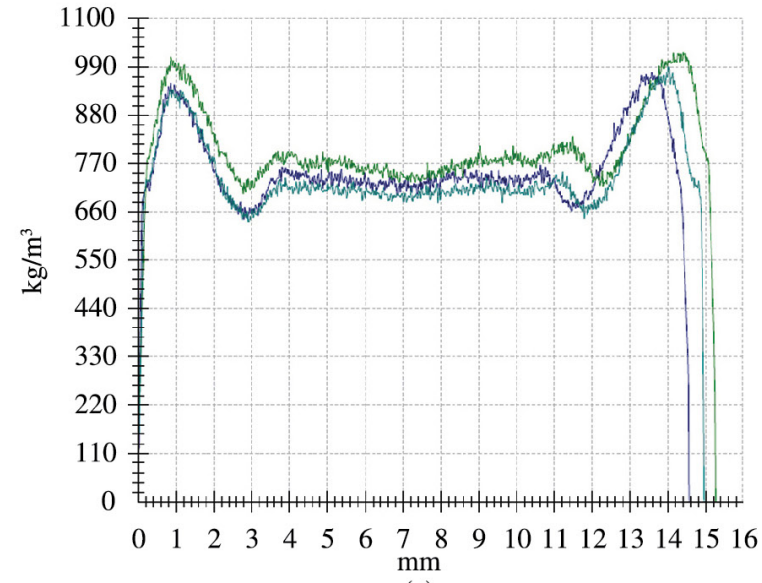

(a)

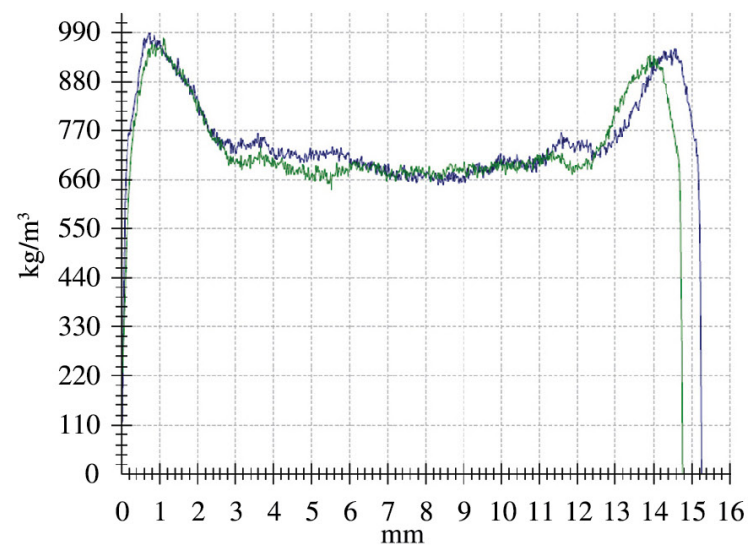

(c)

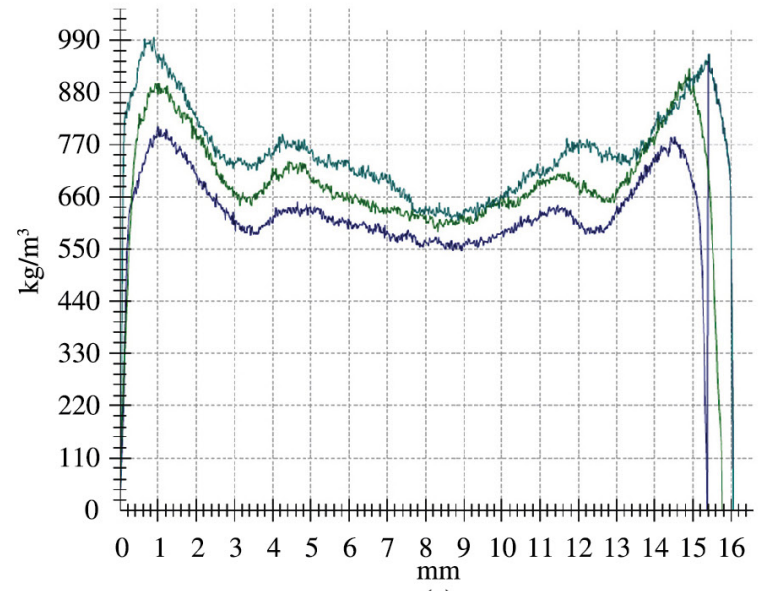

(e)
Furthermore, the standard provides a tolerance of $\pm 7 \%$ in the values of apparent density along the thickness of the panel a standard not met by panels made with $100 \%$ bagasse $^{18}$. This result demonstrates the necessity of adjustment of the feedstock and pressing cycle parameters (eg moisture from the fibers, pressing time, temperature of the press plate, pressure application curve $)^{6}$.

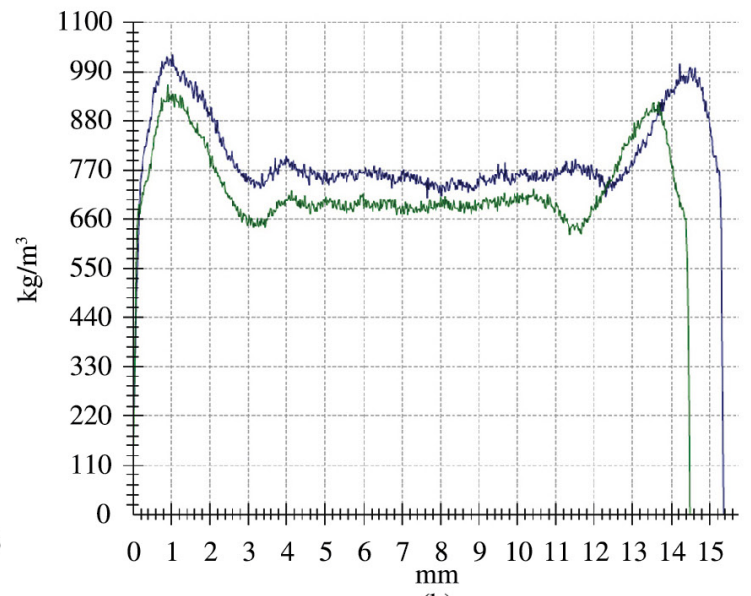

(b)

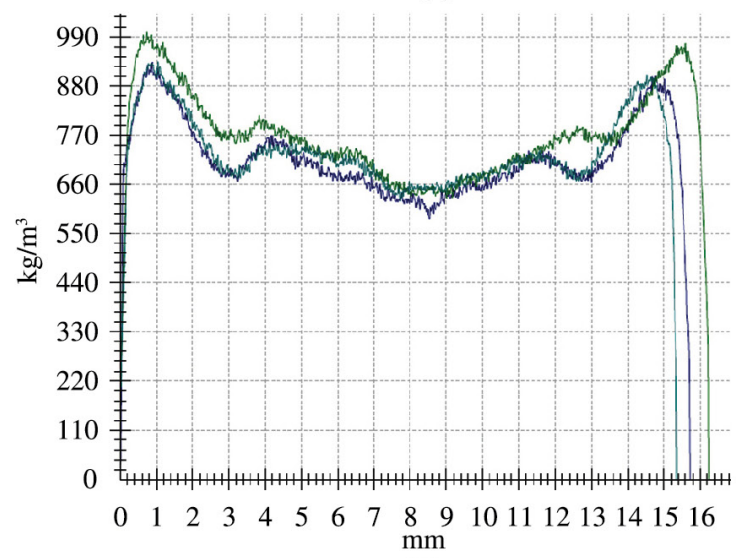

(d)

Figure 3. Density profiles along the panels thickness, step A with $14 \%$ resin. (A) $100 \%$ eucalyptus, (B) $25 \%$ bagasse and $75 \%$ eucalyptus (C) $50 \%$ bagasse and $50 \%$ eucalyptus, (D) $75 \%$ bagasse and $25 \%$ eucalyptus; (E) $100 \%$ bagasse. 
The panel density profiles indicate the use of $50 \%$ bagasse (Figure 3C) in admixture with eucalyptus fibers to be viable, without requiring substantial changes in the press cycle variables.

The density profile with ideal technological properties is characterized by a high density $\left(\sim 1000 \mathrm{~kg} \mathrm{~m}^{-3}\right)$ outer layer (cover), giving the panel a non-porous surface suitable for painting, laminating and lower density and homogeneity in its interior $\left(\sim 650 \mathrm{~kg} \mathrm{~m}^{-3}\right)$, favoring its milling and machining and contributing to greater strength ${ }^{19}$. The average, minimum and maximum bulk density values of the panels vary from 687 to 733 , from 580 to 696 and from 912 to $993 \mathrm{~kg} \mathrm{~m}^{-3}$, respectively, with decreasing trend in density with increasing percentage of bagasse particles without, however, statistically significant difference (Table 2).

Step B: apparent density profiles along the thickness of the panels with 0-5-10-15-20-25\% bagasse (Figure 4) are likewise characterized by higher density $\left(958 \mathrm{~kg} \mathrm{~m}^{-3}\right)$ on the face, with gradual reduction and lower density $\left(670 \mathrm{~kg} \mathrm{~m}^{-3}\right)$ in the center, with a tendency to stabilize in the interior of the panel. As discussed for the panels of Step A, the bulk density profile of the different panels is similar to the letter "M".

For $100 \%$ eucalyptus fiber panels (Figure 4A) there are differences in the values of maximum and minimum density of $1036-839 \mathrm{~kg} \mathrm{~m}^{-3}$ and $748-582 \mathrm{~kg} \mathrm{~m}^{-3}$, respectively, possibly due to the fiber mat moisture values in the pre-press process. However, these panels exhibit uniformy density in their inner layer, meeting the quality and application parameters.

For the panels of the other treatments (Figures 4B-F) there is similarity in in the shape of the internal profiles for each treatment.
Possibly, the apparent density variation in the inner region of the panels is due to the particle size of the bagasse fragments, that present a coarser morphology compared to eucalyptus fibers, and the percentage of resin applied.

The apparent density profiles along the thickness of the panels with $0-5-10-15-20-25 \%$ of bagasse (Figure 5) repeat the pattern of variation (letter "M") observed in previous tests. The internal variations in density of the $100 \%$ eucalyptus fiber panels were reduced in relation to the final moisture of the mat.

For the panels of the other treatments (Figure 5B-F) there is similarity in the shape of the internal profiles for each treatment and compared to profiles of step B/13\% resin.

The panel density values, with emphasis on the surface layer $\left(>1000 \mathrm{~kg} \mathrm{~m}^{-3}\right)$ are related to the results of the physicomechanical assays, with respect to modulus of rupture ${ }^{6}$.

The average apparent density values (maximum, average and minimum) of the panels at $13 \%$ Resin (Table 2) indicate greater heterogeneity in the minimum density values through the significant differences between averages. For panels with $16 \%$ resin (Table 2), all density values have minimum statistical similarity and indicate that this higher resin dosage provided greater homogeneity in the central region of the panel, reflecting in better physical and mechanical properties $^{11}$.

Also, images obtained by scanning electron microscopy (SEM) permit the visualization of anatomical and morphological details of the inner regions and surface of the panels, which can be considered complementary to the density profile analysis.

Table 2. Maximum, medium and minimum density from profiles obtained in GreCon densitometer, by stage and treatment.

\begin{tabular}{|c|c|c|c|c|}
\hline \multirow{2}{*}{ Step } & \multirow{2}{*}{ Treatment } & \multicolumn{3}{|c|}{ Mean densities $\left(\mathrm{kg} \mathrm{m}^{-3}\right)$} \\
\hline & & máximum & medium & mínimum \\
\hline \multirow{5}{*}{$\mathbf{A}$} & $100 \%$ eucalypt & $969 \mathbf{a}$ & $720 \mathbf{a}$ & $664 \mathbf{a}$ \\
\hline & $25 \%$ bagasse $/ 75 \%$ eucalypt & $993 \mathbf{a}$ & $733 \mathbf{a}$ & $696 \mathbf{a}$ \\
\hline & $50 \%$ bagasse / $50 \%$ eucalypt & $985 \mathbf{a}$ & $716 \mathbf{a}$ & $651 \mathbf{a}$ \\
\hline & $75 \%$ bagasse / $25 \%$ eucalypt & $945 \mathbf{a}$ & $704 \mathbf{a}$ & $640 \mathbf{a}$ \\
\hline & $100 \%$ cana & $912 \mathbf{a}$ & 687 a & $580 \mathbf{a}$ \\
\hline \multirow{6}{*}{ B (13\% UF) } & $100 \%$ eucalypt & $959 \mathbf{a}$ & $739 \mathbf{a b}$ & 667 abc \\
\hline & $5 \%$ bagasse / $95 \%$ eucalypt & $925 \mathbf{a}$ & $717 \mathbf{a}$ & $631 \mathbf{a}$ \\
\hline & $10 \%$ bagasse / $90 \%$ eucalypt & $981 \mathbf{a}$ & $778 \mathbf{b}$ & $707 \mathbf{c}$ \\
\hline & $15 \%$ bagasse / $85 \%$ eucalypt & $938 \mathbf{a}$ & $743 \mathbf{a b}$ & $648 \mathbf{a b}$ \\
\hline & $20 \%$ bagasse / $80 \%$ eucalypt & $944 \mathbf{a}$ & $761 \mathbf{a b}$ & 678 abc \\
\hline & $25 \%$ bagasse / $75 \%$ eucalypt & $1000 \mathbf{a}$ & $766 \mathbf{a b}$ & 690 bc \\
\hline \multirow{6}{*}{ B (16\% UF) } & $100 \%$ eucalypt & $998 \mathbf{a b}$ & $773 \mathbf{a b}$ & $687 \mathbf{a}$ \\
\hline & $5 \%$ bagasse / $95 \%$ eucalypt & $985 \mathbf{a b}$ & $770 \mathbf{a b}$ & $690 \mathbf{a}$ \\
\hline & $10 \%$ bagasse / $90 \%$ eucalypt & $1032 \mathbf{b}$ & $792 \mathbf{a b}$ & $709 \mathbf{a}$ \\
\hline & $15 \%$ bagasse / $85 \%$ eucalypt & $1040 \mathbf{b}$ & $811 \mathbf{b}$ & $727 \mathbf{a}$ \\
\hline & $20 \%$ bagasse / $80 \%$ eucalypt & $1027 \mathbf{b}$ & $771 \mathbf{a b}$ & $684 \mathbf{a}$ \\
\hline & $25 \%$ bagasse $/ 75 \%$ eucalypt & $941 \mathbf{a}$ & $748 \mathbf{a}$ & $671 \mathbf{a}$ \\
\hline
\end{tabular}




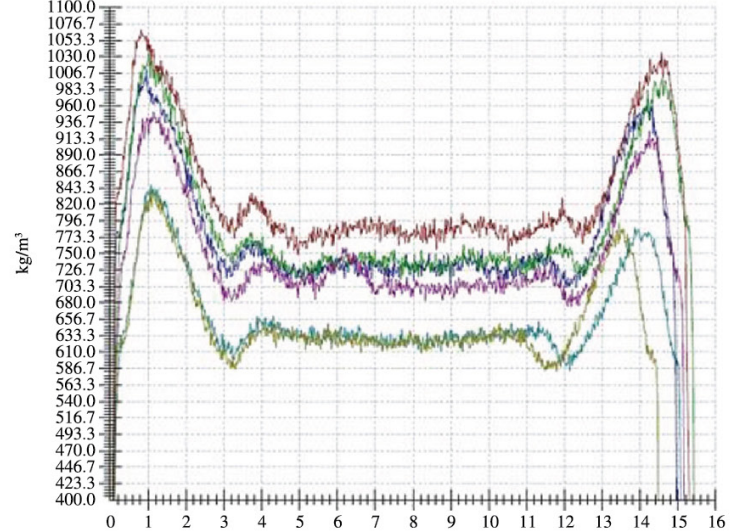

(a)

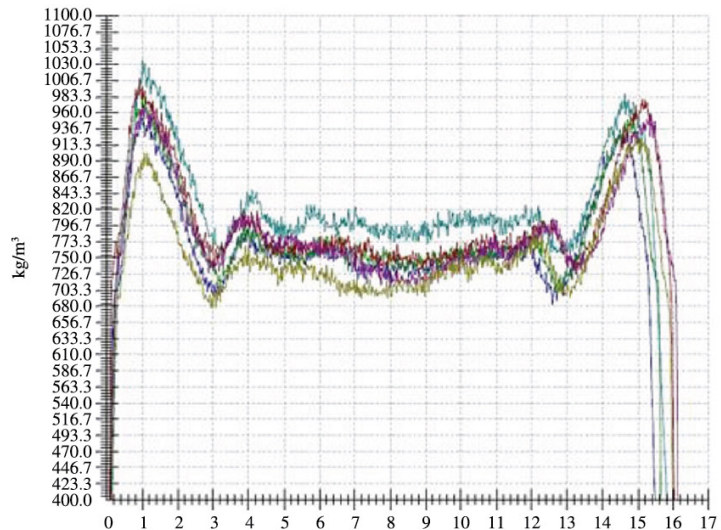

(c)

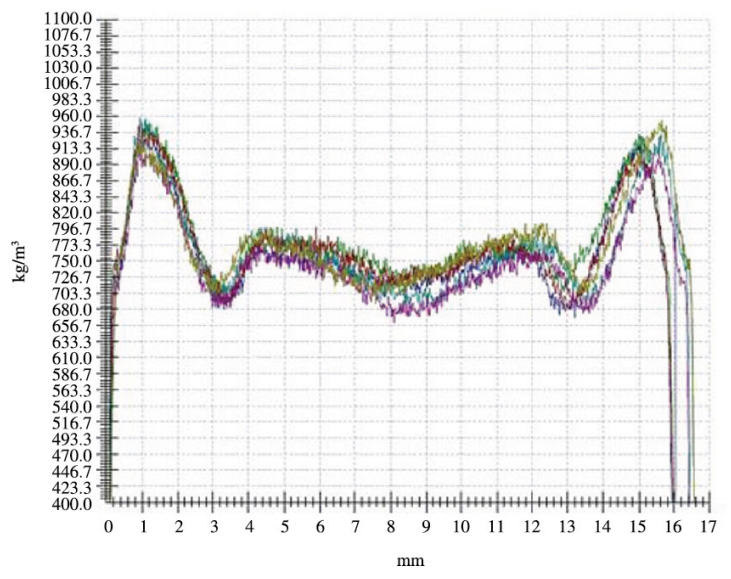

(e)

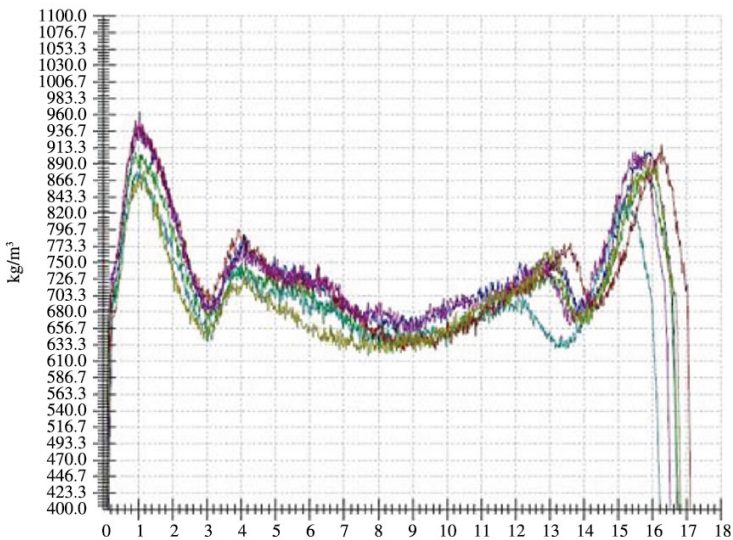

(b)

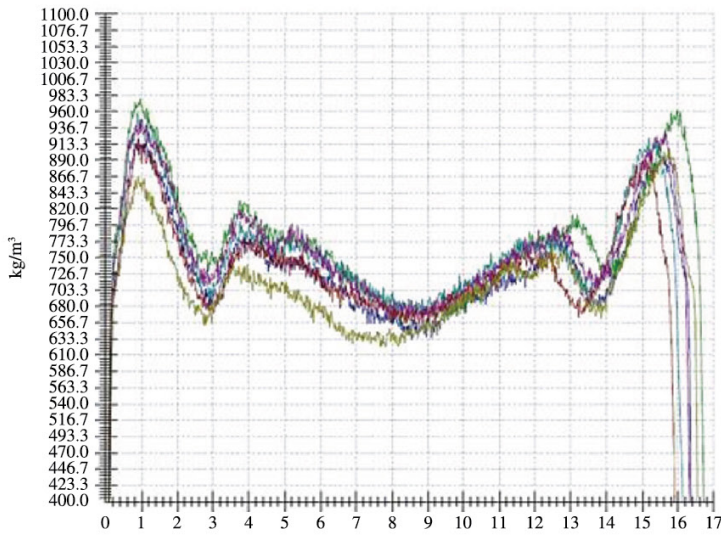

(d)

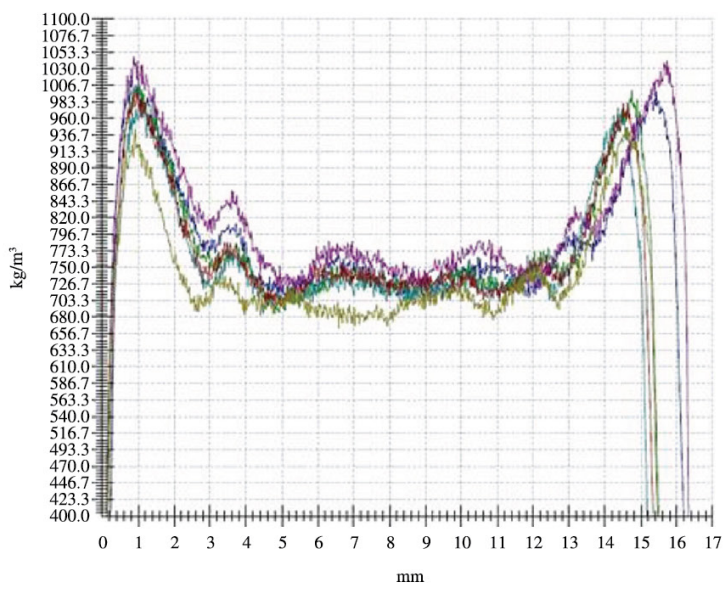

(f)

Figure 4. Density profiles, Step B, with $13 \%$ resin. (A) 100\% eucalyptus, (B) 5\% bagasse and 95\% eucalyptus (C) $10 \%$ bagasse and 90\% eucalyptus, (D) 15\% bagasse and $85 \%$ eucalyptus; (E) $20 \%$ bagasse and $80 \%$ eucalyptus, (F) $25 \%$ bagasse and $75 \%$ eucalyptus. 


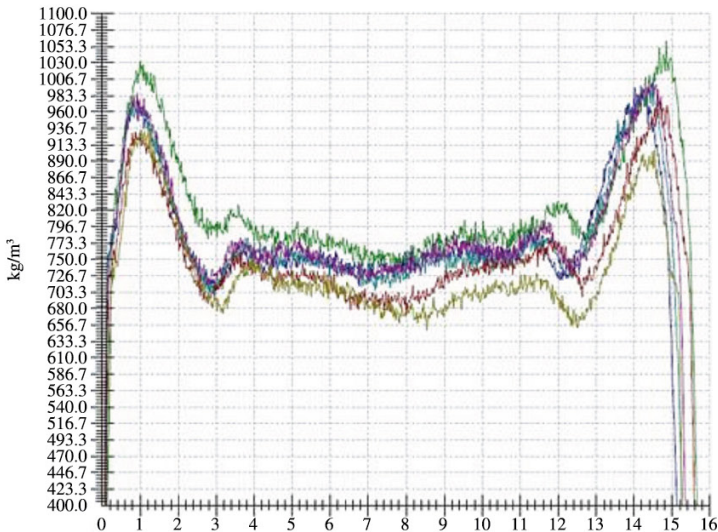

(a)

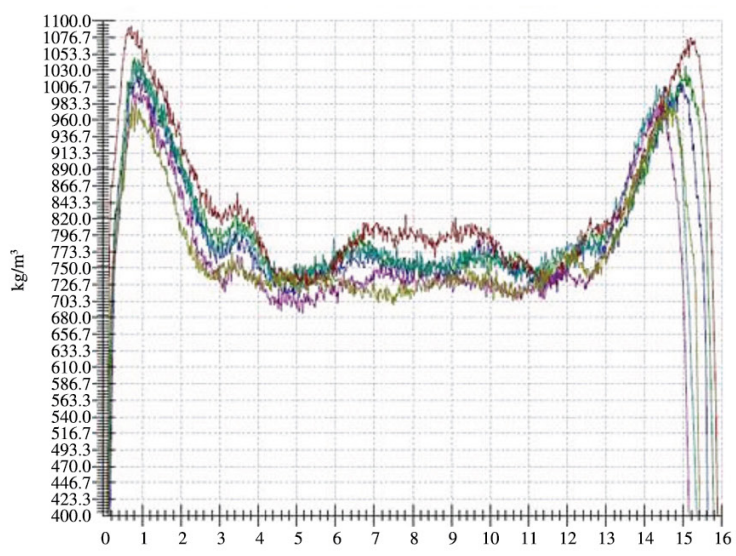

(c)

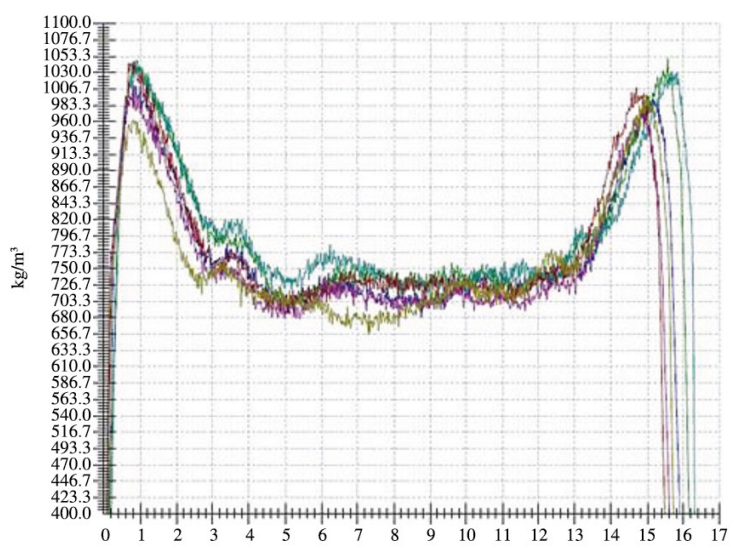

(e)

Figure 5. Density profiles, Step B, with $16 \%$ resin. (A) $100 \%$ eucalyptus, (B) $5 \%$ bagasse and $95 \%$ eucalyptus (C) $10 \%$ bagasse and $90 \%$ eucalyptus, (D) $15 \%$ bagasse and $85 \%$ eucalyptus; (E) $20 \%$ bagasse and $80 \%$ eucalyptus, (F) $25 \%$ bagasse and $75 \%$ eucalyptus.

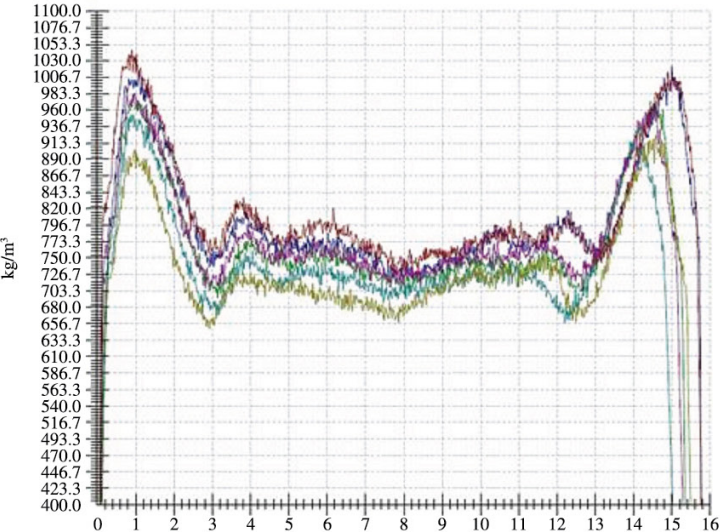

(b)

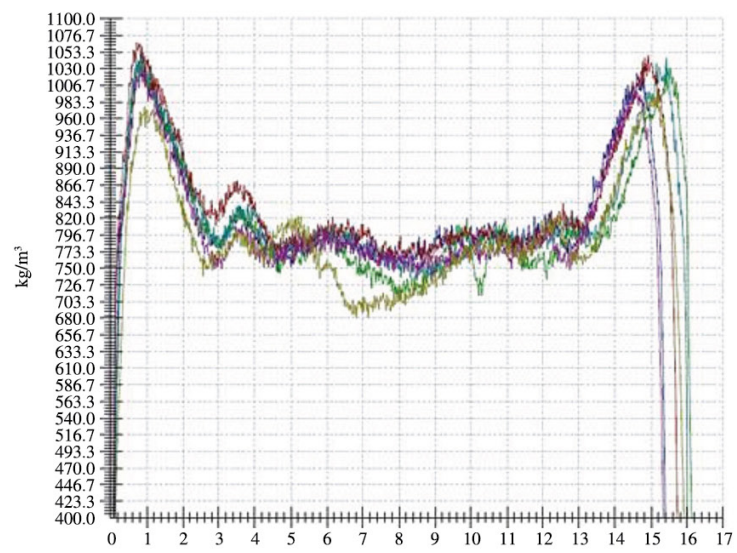

(d)

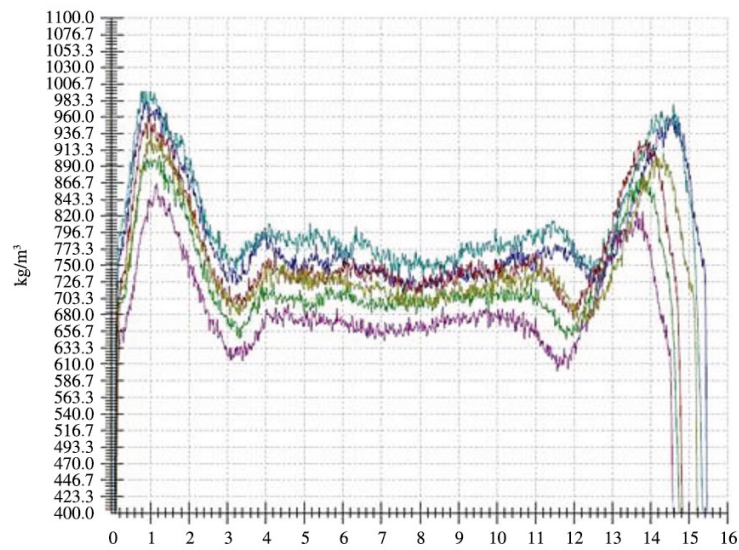

(f)

$\mathrm{mm}$ 


\section{Conclusions}

The density profiles along the thickness of the new panels made from eucalyptus fibers and sugarcane bagasse particles, obtained from X-ray attenuation, showed variations in the structure of the panel, at different levels, depending on the sample thickness, and provided important information on quality, applied to the setting of the pressing conditions and indications of its technological performance, expanding the possibilities of diagnostic parameters of raw materials and new panel manufacturing processes.

\section{References}

1. Feeney FE, Lawlor V and Evertsen JA. An ultrasonic analogue to gamma ray densitometry of medium density fibreboard (MDF). In: Proceedings of 10th International Symposium on Nondestructive Testing of Wood; 1996; Lausane. Lausane; 1996. p. 407.

2. Wang X, Mohammad M, Hu LJ and Salenikovich A. Evaluation of density distribution in wood-based panels using X-ray scanning. Journal of Nondestructive Testing. 2006; 11(4). Available from <http://www.ndt.net/article/v11n04/wang/ wang.htm>. Access: 18/01/2009.

3. Cai Z, Muehl JH and Winandy J. Effects of press schedule on formation of vertical density profile for MDF panels. In: Proceedings of International Wood Composites Symposium; 2006; Seattle. Seattle: Washington State University; 2006. $11 \mathrm{p}$.

4. Belini UL, Tomazello $\mathrm{M} \mathrm{F}^{\mathrm{o}}$ and Chagas MP. Densitometria de raios X aplicada na avaliação tecnológica de painéis MDF de eucalipto. Scientia Forestalis. 2009; 37(84):343-350.

5. Kelly MW. A critical literature review of relation particles between processing parameters and physical properties of particleboard. Madison: US Forest Products Laboratory, 1977.

6. Wong ED, Zhang M, Wang Q, Han G and Kawai S. Formation of the density profile and its effects on the properties of fiberboard. Journal of Wood Science. 2000; 46(1):202-209. http://dx.doi.org/10.1007/BF00776450

7. Woodson GE. Density profile and fiber alignment in fiberboard from three southern hardwoods. Forest Product Journal. 1997; 27(8):29-34.

8. Lee S, Shupe TF and Hse CY. Mechanical and physical properties of agro based fiberboard. Holz als Roh - und Werkstoff. 2006; 64(1):74-79. http://dx.doi.org/10.1007/ s00107-005-0062-z

9. Luz SM, Gonçalves AR and Del'Arco AP Jr. Mechanical behavior and microstructural analysis of sugarcane bagasse fibers reinforced polypropylene composites. Composites: Part A. 2007; 38(1):1455-1461. http://dx.doi.org/10.1016/j. compositesa.2007.01.014
The urea formaldehyde resin was effective at $16 \%$ percent for greater consistency in the format of the profiles that reflected in higher statistical similarity, particularly in the mean minimum density values in the center of the panels, which relate to performance regarding internal bond assays.

\section{Acknowledgements}

The authors wish to express their sincere thanks to the São Paulo Research Foundation (FAPESP), University of São Paulo (USP), Duratex S.A. company and in particular the Engineer José Reinaldo S. Astolphi (in memoriam).

10. Ortunõ TG, Rodrígues JA, García MTF, Villena MF and García CEF. Evaluation of the physical end mechanical properties of particleboard made from giant reed (Arundo donax L.). BioResources. 2011, 6(1):477-486.

11. Belini UL, Tomazello M F , $^{\circ}$ Louzada JLPC, Rodrigues JC and Astolphi JRS. Pilot study for MDF manufacture from sugarcane bagasse and eucalyptus fibers. European Journal of Wood and Wood Products. 2012; 70(4):537-539. http://dx.doi. org/10.1007/s00107-011-0577-4

12. Fiorelli J, Curtolo DD, Garzon NB, Johnson R and Savastano H Jr. Particulate composite based on coconut fiber and castor oil polyurethane adhesive: An ecoefficient product. Industrial Crops and Products. 2012; 40(1):69-75. http://dx.doi. org/10.1016/j.indcrop.2012.02.033

13. União da Industria de Cana-de-Açúcar - UNICA. Cana-deaçúcar processada pelas usinas brasileiras: produção canade-açúcar no Brasil. UNICA; 2010. Available from: <http:// www.unica.com.br/downloads/estatisticas/processcanabrasil. xls>. Access in: 23/02/2010.

14. Associação Brasileira de Produtores de Floresta Plantada - ABRAF. Anuário estatístico da ABRAF: ano base 2009. Brasília; 2009. 140 p.

15. Associação Brasileira da Indústria de Painéis de Madeira - ABIPA. Números. Available from: <http://www. abipa.org.br/numeros.php>. Access in: 28/10/2001.

16. Widyorini R, Xu J, Umemura K and Kawai S. Manufacture and properties of binderless particleboard from bagasse. I: Effects of raw material type, storage methods, and manufacturing process. Journal of Wood Science. 2005; 51(1):648-654. http:// dx.doi.org/10.1007/s10086-005-0713-Z

17. Ayrilmis N. Effect of panel density on dimensional stability of medium and high density fiberboards. Journal of Materials Science. 2007; 42(1):8551-8557. http://dx.doi.org/10.1007/ s10853-007-1782-8

18. European Standard. EN 622-1: fibreboards - specifications. Part 1: General requeriments. Bruxelas; 2003. 9 p.

19. Moarcas $\mathrm{O}$ and Irle M. Internal bond, MOE, MOR and density profiles of C4M $18 \mathrm{~mm}$ thick particleboards. In: Proceedings of 1th European Panel Products Symposium; 1997; Llandudno. Llandudno; 1997. 